\title{
Global between-countries variance in SARS-CoV-2 mortality is driven by reported prevalence, age distribution, and case detection rate
}

Objective: To explain the global between-countries variance in number of deaths per million citizens $\left(n D_{p m}\right)$ and case fatality rate $(C F R)$ due to severe acute respiratory syndrome coronavirus 2 (SARS-CoV-2) infection.

Design: Systematic analysis.

Data sources: Worldometer, European Centre for Disease Prevention and Control, United Nations

Main outcome measures: The explanators of $n D_{p m}$ and $C F R$ were mathematically hypothesised and tested on publicly-available data from 88 countries with linear regression models on May $1^{\text {st }}$ 2020. The derived explanators - age-adjusted infection fatality rate (IFRadj) and case detection rate $(C D R)$ - were estimated for each country based on a SARS-CoV-2 model of China. The accuracy and agreement of the models with observed data was assessed with $R^{2}$ and Bland-Altman plots, respectively. Sensitivity analyses involved removal of outliers and testing the models at five retrospective and four prospective time points.

Results: Globally, IFR $R_{a d j}$ estimates varied between countries, ranging from below $0.2 \%$ in the youngest nations, to above $1.3 \%$ in Portugal, Greece, Italy, and Japan. The median estimated global CDR of SARS-CoV-2 infections on April $16^{\text {th }} 2020$ was $12.9 \%$, suggesting that most of the countries have a much higher number of cases than reported.

At least $93 \%$ and up to $99 \%$ of the variance in $n D_{p m}$ was explained by reported prevalence expressed as cases per million citizens $\left(n C_{p m}\right), I F R_{a d j}$, and $C D R$. IFR $R_{a d j}$ and $C D R$ accounted for up to $97 \%$ of the variance in $C F R$, but this model was less reliable than the $n D_{p m}$ model, being sensitive to outliers ( $R^{2}$ as low as $67.5 \%$ ).

Conclusions: The current differences in SARS-CoV-2 mortality between countries are driven mainly by reported prevalence of infections, age distribution, and $C D R$. The $n D_{p m}$ might be a more stable estimate than CFR in comparing mortality burden between countries.

\section{Introduction}

The severe acute respiratory syndrome coronavirus 2 (SARS-CoV-2) has substantially affected the lives of billions of people. $(1,2)$ An ongoing question in the public is how high is the direct mortality caused by SARS-CoV-2. Observations in the case fatality rate $(C F R)$, i.e. the proportion of individuals with a confirmed SARS-CoV-2 infection who die, has raised concerns due to the high variability between countries, ranging from below $0.1 \%$ in Qatar and Singapore to above 15\% in Belgium and France, on May $27^{\text {th }}$ $2020 .(3,4)$

The global average case detection rate

\footnotetext{
1 Science for Life Laboratory; Department of Oncology and Pathology, Karolinska Institute, Stockholm, Sweden;

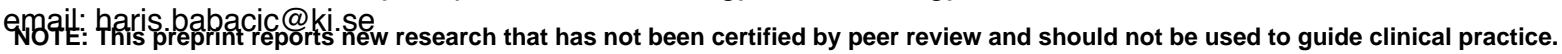


medRxiv preprint doi: https://doi.org/10.1101/2020.05.28.20114934; this version posted June 2, 2020. The copyright holder for this preprint

(which was not certified by peer review) is the author/funder, who has granted medRxiv a license to display the preprint in perpetuity. It is made available under a CC-BY-NC-ND 4.0 International license .

$(C D R)$ on March $30^{\text {th }}$ was estimated at $9 \%$, suggesting that the true prevalence of infections is likely underestimated in most of the countries.(9) Studies suggest that the reported number of cases per million citizens $\left(n C_{p m}\right)$ is probably lower than the true number of infected individuals, and that this contributes to the varying CFR between countries. $(5,6) \quad C F R$ appears higher than the true infection fatality rate (IFR), i.e. the true proportion of individuals with a SARS-CoV-2 infection who will die in the population regardless of whether they are confirmed or not.(7) This was observed in China where the crude CFR estimate was $3.67 \%$, whereas the age-adjusted overall IFR (IFR adj $)$ was estimated at $0.66 \% .(8)$

The number of confirmed deaths per million citizens $\left(n D_{p m}\right)$ is a population-normalised measure of mortality used to compare countries. However, the varying $n D_{p m}$ in countries with similar $n C_{p m}$, population size and similar mitigation strategies has also raised fears of potential varying virulence of the virus and different treatment capacity between countries. A recent multivariable model could explain only $62.5 \%$ of SARSCoV-2 mortality variance between countries.(10) Explaining the remaining variance of the reported mortality as $n D_{p m}$ and $C F R$ is extremely relevant for both the medical community and the public, to address public concerns. Furthermore, it is important to assess whether the adjusted mortality differs substantially between countries, in order to track the success of different strategies.

The aim of this study was to test two mathematical hypotheses that explain the global between-countries variance in SARS-CoV-2 mortality expressed as $n D_{p m}$ and $C F R$ on real data.

\section{Methods}

\section{Data sources}

Global data on cumulative number of cases $(n C)$, cumulative number of deaths $(n D)$, cumulative number of tests $(n T)$, number of tests per million citizens $\left(n T_{p m}\right)$, number of cases per million citizens $\left(n C_{p m}\right)$, and $n D_{p m}$ per country were downloaded from
Worldometer.(3) Global data on number of new cases and deaths per day were downloaded from the European Centre for Disease Prevention and Control (ECDC).(4) Global data on age distribution and 2018 GDP per country were obtained from United Nations (UN) statistics. $(11,12)$

\section{Derivation of hypotheses}

The overall IFRadj per country was estimated and weighed per nine age groups, following the equation:

$$
I F R_{a d j}=\frac{\sum_{i=1}^{9} n_{i} \times I F R_{i}}{N}
$$

where $I F R_{a d j}$ is the $I F R_{a d j}$ in percentages (\%), $N$ is the total population size, $n_{i}$ is the number of susceptible individuals within an age group, $I F R_{i}$ is the IFR for that age group in \% as estimated by Verity and colleagues.(8) For the purposes of this study, the $I F R_{a d j}$ serves as an ageadjustment factor.

The CDR per country was estimated as the percentage of the estimated cases that have been confirmed cases, following the approach of Vollmer \& Bommer (9):

$$
C D R_{i}=\frac{n C_{\tau i}}{n D_{\tau j} \times \frac{100}{I F R_{i}}} \times 100 \%
$$

where $C D R_{i}$ is $C D R$ in \%,IFR is $I F R_{a d j}$ in $\%, n C_{\tau i}$ is cumulative number of confirmed cases at time $\tau i$, and $n D_{\tau j}$ is cumulative number of confirmed deaths at time $\tau j$. Following the Verity model(8), $\tau i$ is 14 days before $\tau j$ in this approach, based on the estimate that on average 18.8 days pass from the onset of symptoms to death, holding a conservative assumption that on average 4.8 days pass from symptom onset to case detection.

From these equations, $n D_{\tau j}$ is implied to have an inverse relation with the $C D R_{i}$ and will depend on the cumulative number of cases 14 days before the $n D_{\tau j}$ have occurred, and the age-adjusted $I F R_{i}$ :

$$
n D_{\tau j}=\frac{n C_{\tau i} \times I F R_{i}}{C D R_{i}}
$$

Assuming that the number of cases at the time of $n D_{\tau j}\left(n C_{\tau j}\right)$ will have a constant dependence on the $n C_{\tau i}$, as observed repeatedly in epidemics, including SARSCoV-2, $n C_{\tau j}$ can replace it in the equation. In order to explain the population- 
medRxiv preprint doi: https://doi.org/10.1101/2020.05.28.20114934; this version posted June 2, 2020. The copyright holder for this preprint

(which was not certified by peer review) is the author/funder, who has granted medRxiv a license to display the preprint in perpetuity. It is made available under a CC-BY-NC-ND 4.0 International license .

normalised number of deaths - $n D_{p m}$, one has to normalise the $n C_{\tau j}$ per population size with $n C_{p m}$, deriving that:

$$
n D_{p m, \tau j}=\frac{n C_{p m, \tau j} \times I F R_{i}}{C D R_{i}} \text { [hypothesis 1], }
$$

where $n D_{p m}$ at time $\tau j$ will be higher in countries with higher $n C_{p m}$ at time $\tau j$ and higher IFR $R_{a d j}$, whereas it will be lower in countries with the same $n C_{p m}$ and IFR $R_{a d j}$ that have higher $C D R$.

Following that the CFR is the proportion of $n D_{\tau j}$ from the $n C_{\tau j}$, the subsequent relationship between the $C F R$, the IFR $R_{a d j}$ and $C D R$ is implied as:

$$
C F R_{i}=\frac{n C_{\tau i} \times I F R_{i}}{n C_{\tau j} \times C D R_{i}}
$$

where $C F R_{i}$ is the CFR of a country, $I F R_{i}$ is the IFR adj of a country, $n C_{\tau j}$ is the cumulative number of cases on the day of $n D_{\tau j}$, and $n C_{\tau i}$ is the cumulative number of cases two weeks before $\tau j$. Again, assuming that $n C_{\tau j}$ will have a constant dependence on the $n C_{\tau i}$, they can be omitted from the equation, deriving that:

$$
C F R_{i}=\frac{I F R_{i}}{C D R_{i}} \quad \text { [hypothesis 2], }
$$

where the $C F R$ will be higher in countries with higher IFR $R_{a d j}$ and will have an inverse relation with the $C D R$. Hypothesis 2 implies that older countries will have higher CFR and countries with higher $C D R$ will have lower $C F R$, and predicts that the $n C_{\tau j}$ will not drive $C F R$.

\section{Testing hypotheses on real data}

To test hypothesis 1 , we built linear regression model $1 \quad\left(n D_{p m}\right.$ model $)$, to explain $n D_{p m}$ with $n C_{p m}$, IFR $R_{a d j}$, and $C D R$. To test hypothesis 2, we built linear regression model 2 (CFR model), to explain $C F R$ with $I F R_{a d j}$ and $C D R$. Only countries with more than 1,000 cases were included in the analyses. All variables were normalised by log transformation. We have additionally tested whether GDP, $n T_{p m}$, and duration of epidemic (as days from first case) could explain the mortality after being added to the models.(10) The accuracy was assessed with $R^{2}$, and the agreement was analysed graphically with the BlandAltman mean difference plot.(13)
Sensitivity analyses. To address uncertainty, we removed outliers outside of the $95 \%$ confidence intervals $(95 \% \mathrm{Cl})$ of the Bland-Altman plots, and reiterated the analyses retrospectively on April $4^{\text {th }}, 8^{\text {th }}$, $12^{\text {th }}, 21^{\text {st }}, 24^{\text {th }}$, and prospectively on May $7^{\text {th }}, 11^{\text {th }}, 18^{\text {th }}$, and $27^{\text {th }} 2020$.

\section{Data and code availability}

The study is conducted according to the Guidelines for Accurate and Transparent Health Estimates Reporting.(14) The code, data, and results are publicly available at https://github.com/harbab/covid 19 morta lity. All analyses were performed in $R$ V.3.6.1.

\section{Results \\ Descriptive statistics}

As of May $1^{\text {st }} 2020$, a total of 214 countries in the world have reported SARS-CoV-2 infections. Of these, 88 countries have reported more than 1,000 SARS-CoV-2 infections. The estimated IFR $R_{\text {adj }}$ varied from below $0.2 \%$ in the youngest nations of Ivory Coast, Guinea, Nigeria, UAE, Cameroon, and Afghanistan, up to above $1.3 \%$ in the world's oldest nations of Germany, Portugal, Greece, Italy, and highest in Japan with $1.6 \%$. The global average $C D R$ on April 16 2020 was $22.12 \%$ (median: $12.9 \%$, SD: 32.47 ), suggesting that most of the cases were undetected. Only two countries detected more than $100 \%$ of expected cases - Iceland (154.50\%) and Singapore (234.95\%). Estimates for each country are shown in Table S1, supplementary information.

\section{Model $1-n D_{p m}$}

Univariate analyses showed that $n C_{p m}$, IF $R_{a d j}$, and $n T_{p m}$ could explain $65.57 \%$, $40.29 \%$, and $25.91 \%$ of the variance in $n D_{p m}$, respectively $\left(\mathrm{p}<3.922^{-07}\right)$. The $C D R$ was not univariately associated with $n D_{p m}$ $(p=0.738)$. However, combined together $n C_{p m}$, IFR $R_{a d j}$ and $C D R$ could explain $97.18 \%$ of the variance in $n D_{p m}\left(p<2.2^{-16}\right)$. Introducing $n T_{p m}$ to the model only slightly improved the $R^{2}$ to $0.9728\left(\mathrm{p}<2.2^{-16}\right)$. All four variables were included in the final model 1 (Table 1). The relationship 
medRxiv preprint doi: https://doi.org/10.1101/2020.05.28.20114934; this version posted June 2, 2020. The copyright holder for this preprint (which was not certified by peer review) is the author/funder, who has granted medRxiv a license to display the preprint in perpetuity. It is made available under a CC-BY-NC-ND 4.0 International license.

Table 1. Linear model 1 - explaining the log-transformed citizens $n D_{p m}$. The model had a residual standard error of 0.3073 on 79 degrees of freedom (4 observations with missing data). Multiple $R^{2}=0.9741$, adjusted $R^{2}=0.9728$. F-statistic: 743.8 on 4 and $79 \mathrm{DF}, \mathrm{p}$-value: $<2.2^{-16}$.

\begin{tabular}{|c|c|c|c|c|c|c|}
\hline Coefficient & Estimate & $95 \% \mathrm{Cl}$ & Std. error & t-value & $\mathrm{p}$-value & significance \\
\hline Intercept & -0.9277 & $-1.3786,-0.4769$ & 0.227 & -4.096 & 0.0001 & $\star \star \star \star ~$ \\
\hline $\log \left(I F R_{a d j}\right)$ & 1.2951 & $1.1656,1.4246$ & 0.065 & 19.907 & $1.61^{-32}$ & *** \\
\hline $\log \left(n C_{p m}\right)$ & 0.9432 & $0.8647,1.0216$ & 0.039 & 23.931 & $6.03^{-38}$ & *** \\
\hline $\log (C D R)$ & -0.9899 & $-1.0785,-0.9012$ & 0.045 & -22.218 & $1.01^{-35}$ & *** \\
\hline $\log \left(n T_{p m}\right)$ & 0.0922 & $0.0071,0.1774$ & 0.043 & 2.156 & 0.0341 & * \\
\hline
\end{tabular}

${ }^{\star \star \star}$, statistically highly significant; ${ }^{*}$, statistically low significance.

between the variables was as hypothesised mathematically. The model showed almost perfect accuracy (Figure $1 \mathrm{~A})$ and high agreement (Figure 1B) in explaining $n D_{p m}$. Some countries were outliers (Figure 1C).

Univariately, $n D_{p m}$ had a positive association with GDP $\left(p=8.213^{-11}\right)$ and the duration of the epidemic (0.0227). However, neither variable had an association with $n D_{p m}$ when added to model 1 ( $p=0.308$ and 0.196 , respectively). GDP had a positive correlation with all four explanators of model $1\left(p<9.341^{-06}\right)$, most evidently with $n T_{p m}\left(R^{2}=0.592\right)$, and was thus redundant in the model. GDP and duration of epidemic are possibly unstable explanators that can be useful in stratified analyses per continents and regions.

\section{Model 2 - CFR}

Univariately, IFR $R_{a d j}$ and $C D R$ explained $17.68 \%$ and $40.35 \%$ of the variance in $C F R$, respectively. When combined together, IFR $R_{a d j}$ and $C D R$ accounted for $91.84 \%$ of the variance in CFR (Table 2). The predicted CFR also had high accuracy and high agreement with observed CFR (Figure 2). Both $n C_{p m}$ and $n C_{\tau j}$ were not associated with the CFR when added to model 2 independently, confirming the assumption on which hypothesis 2 relies. None of the additional variables $\left(n T_{p m}\right.$,
GDP, or duration of epidemic) was associated with CFR univariately or when added to model 2. $n T_{p m}$ and GDP were also not associated with $C F R$ in a previous report (10).

\section{Sensitivity analyses}

Reiterating the analysis at five retrospective and four prospective timepoints showed that model 1 could robustly explain at least $93 \%$ of the variance in $n D_{p m}$ (at least $95 \%$ after removing outliers), but model 2 had lower accuracy at earlier stages of the pandemic (Figure 3). Less countries had $>1,000$ cases at earlier timepoints (range: 56 on April $4^{\text {th }}-110$ on May $\left.27^{\text {th }}\right)$. The $n T_{p m}$ was an unreliable explanator of $n D_{p m}$ that accounted for a very small proportion of variance that can be omitted; the effect of $n T p m$ is possibly underestimated due to its association with $n C_{p m}$.

The CFR model was more sensitive to outliers compared to the $n D_{p m}$ model, with a higher average decrease in $R^{2}$ of $5.53 \%$ (range: $1.4-9.6 \%$, median: $5.85 \%$ ) compared to an average decrease of $1.59 \%$ for the $n D_{p m}$ model (range: $0.5-$ $3.4 \%$, median: $1.2 \%$ ) when including outliers $(p=0.0035)$. The assumption of no effect of $n C_{\tau j}$ on CFR was violated at some time-points.

Table 2. Linear model 2 - explaining the log-transformed $\boldsymbol{C F R}$. The model had a residual standard error of 0.3126 on 84 degrees of freedom ( 1 missing data). Multiple $R^{2}=0.9203$, adjusted $R^{2}=0.9184$. F-statistic: 485 on 2 and $84 \mathrm{DF}, \mathrm{p}$-value: $<2.2^{-16}$.

\begin{tabular}{lrrrrrr}
\hline Coefficient & Estimate & $95 \% \mathrm{Cl}$ & Std. error & t-value & p-value & significance \\
\hline Intercept & 4.0300 & $3.8188,4.2412$ & 0.1062 & 37.9440 & $1.22^{-54}$ & $* \star *$ \\
$\log (C D R)$ & -0.9366 & $-1.0048,-0.8685$ & 0.0343 & -27.3358 & $1.42^{-43}$ & $* * *$ \\
$\log \left(I F R_{a d j}\right)$ & 1.3290 & $1.2150,1.4430$ & 0.0573 & 23.1818 & $2.93^{-38}$ & $* \star *$ \\
\hline$\star * \star$ statistically highly significant & & & & &
\end{tabular}


medRxiv preprint doi: https://doi.org/10.1101/2020.05.28.20114934; this version posted June 2, 2020. The copyright holder for this preprint (which was not certified by peer review) is the author/funder, who has granted medRxiv a license to display the preprint in perpetuity.

A

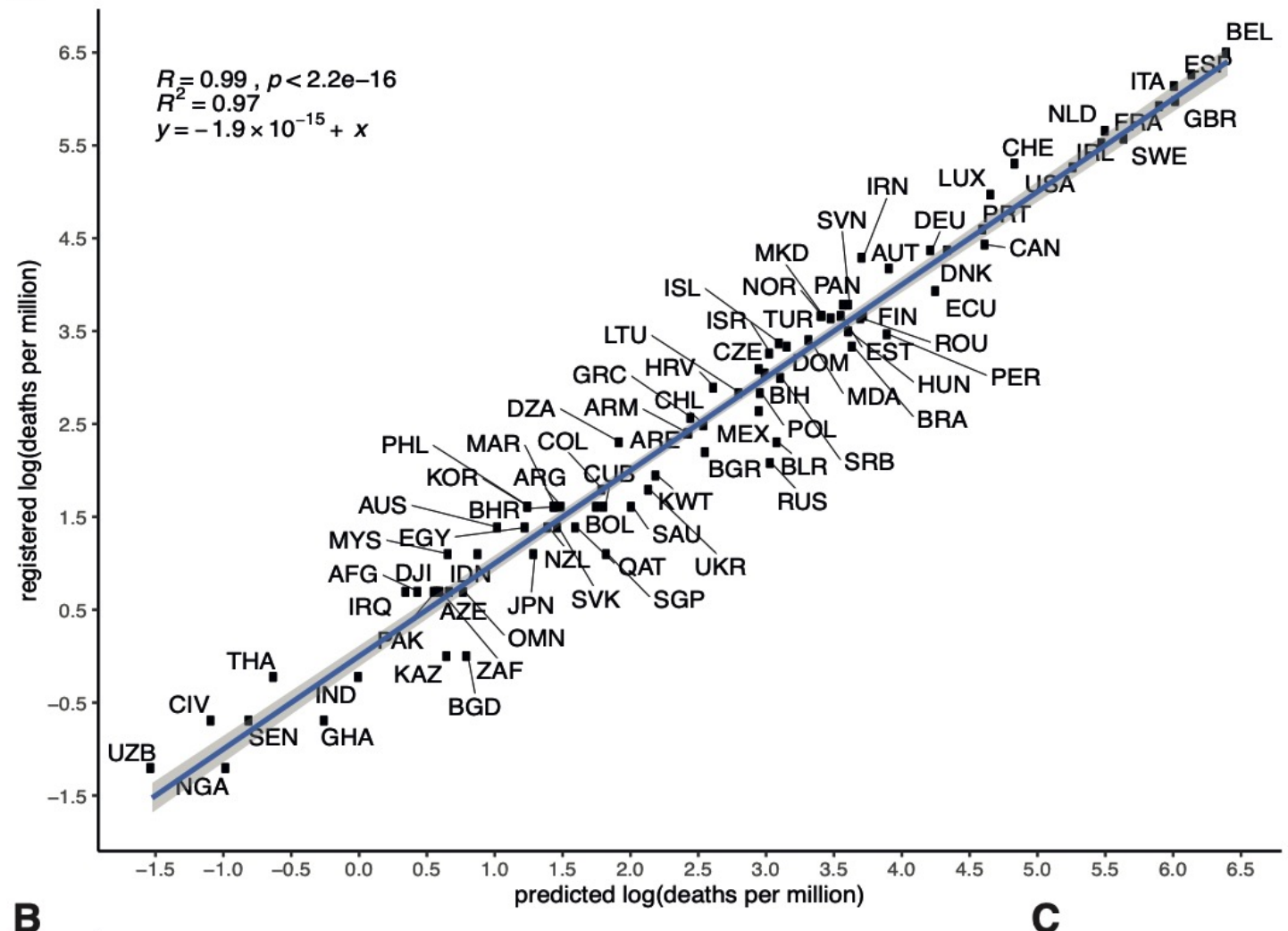

B
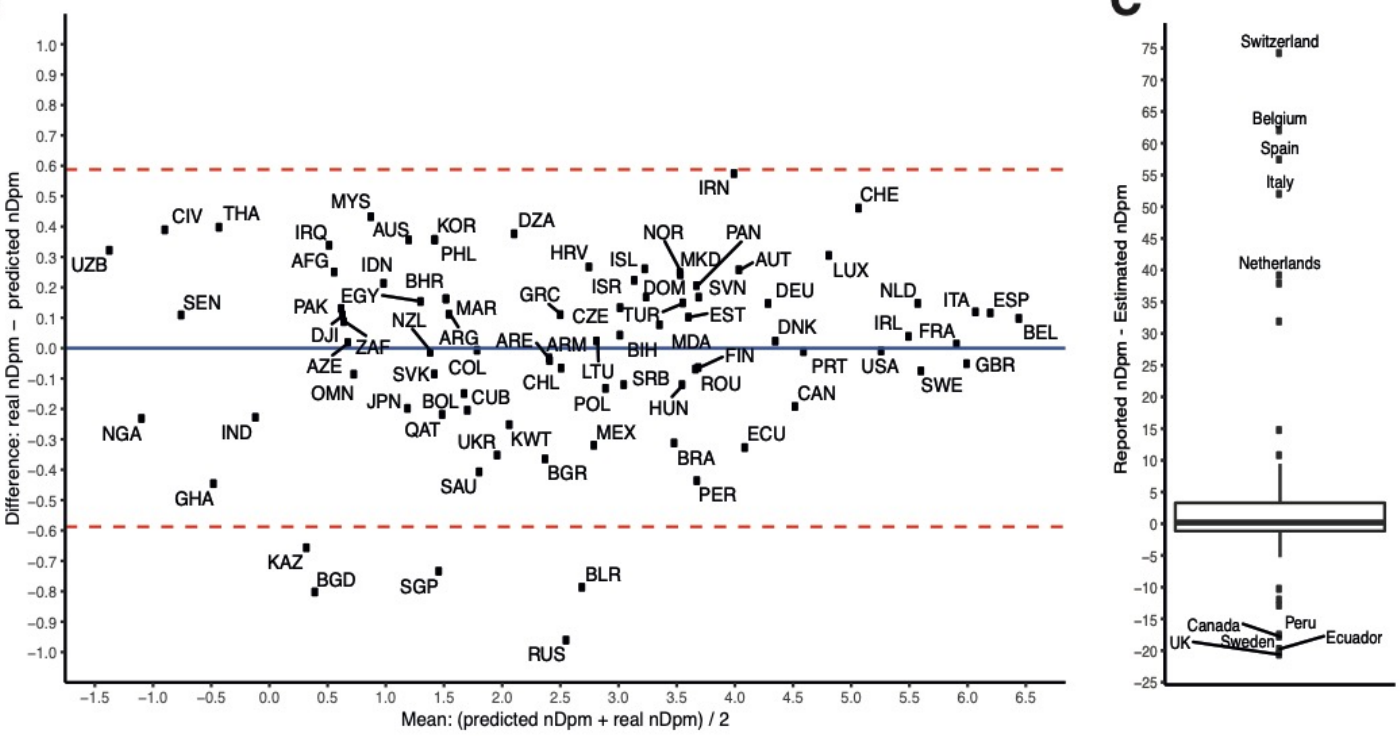

Figure 1. Agreement between predicted and observed deaths per million citizens $\left(n D_{p m}\right)$. The countries are annotated with their country code. A. Predicted log-normalised $n D_{p m}$ (x axis) vs lognormalised observed $n D_{p m}$ (y axis). The model could almost perfectly predict the $n D_{p m}$ in a linear fashion. The blue line is model fit and the shades are $95 \% \mathrm{Cl}$; B. Bland-Altman plot. The mean of the predicted log-normalised $n D_{p m}$ and observed log-normalised $n D_{p m}$ is plotted on the $\mathrm{x}$ axis, whereas the difference on a log scale between the observed $n D_{p m}$ and predicted $n D_{p m}$ is plotted on the y axis. The mean difference between the observed $n D_{p m}$ and predicted $n D_{p m}$ was 0 (blue, full line), with the $95 \%$ confidence intervals (red, dashed lines) containing most of the values. Five countries were outliers in this model, having less $n D_{p m}$ than predicted: Russia, Belarus, Singapore, Bangladesh, and Kazakhstan; C. Countries outliers. Actual difference between observed $n D_{p m}$ and predicted $n D_{p m}$ in numbers. The labelled countries in the upper part of boxplot ( $>95^{\text {th }}$ quantile) had much more observed $n D_{p m}$ than predicted, whereas the labelled countries in the lower part had much less $n D_{p m}$ than predicted by the model. 
medRxiv preprint doi: https://doi.org/10.1101/2020.05.28.20114934; this version posted June 2, 2020. The copyright holder for this preprint (which was not certified by peer review) is the author/funder, who has granted medRxiv a license to display the preprint in perpetuity. It is made available under a CC-BY-NC-ND 4.0 International license.

A

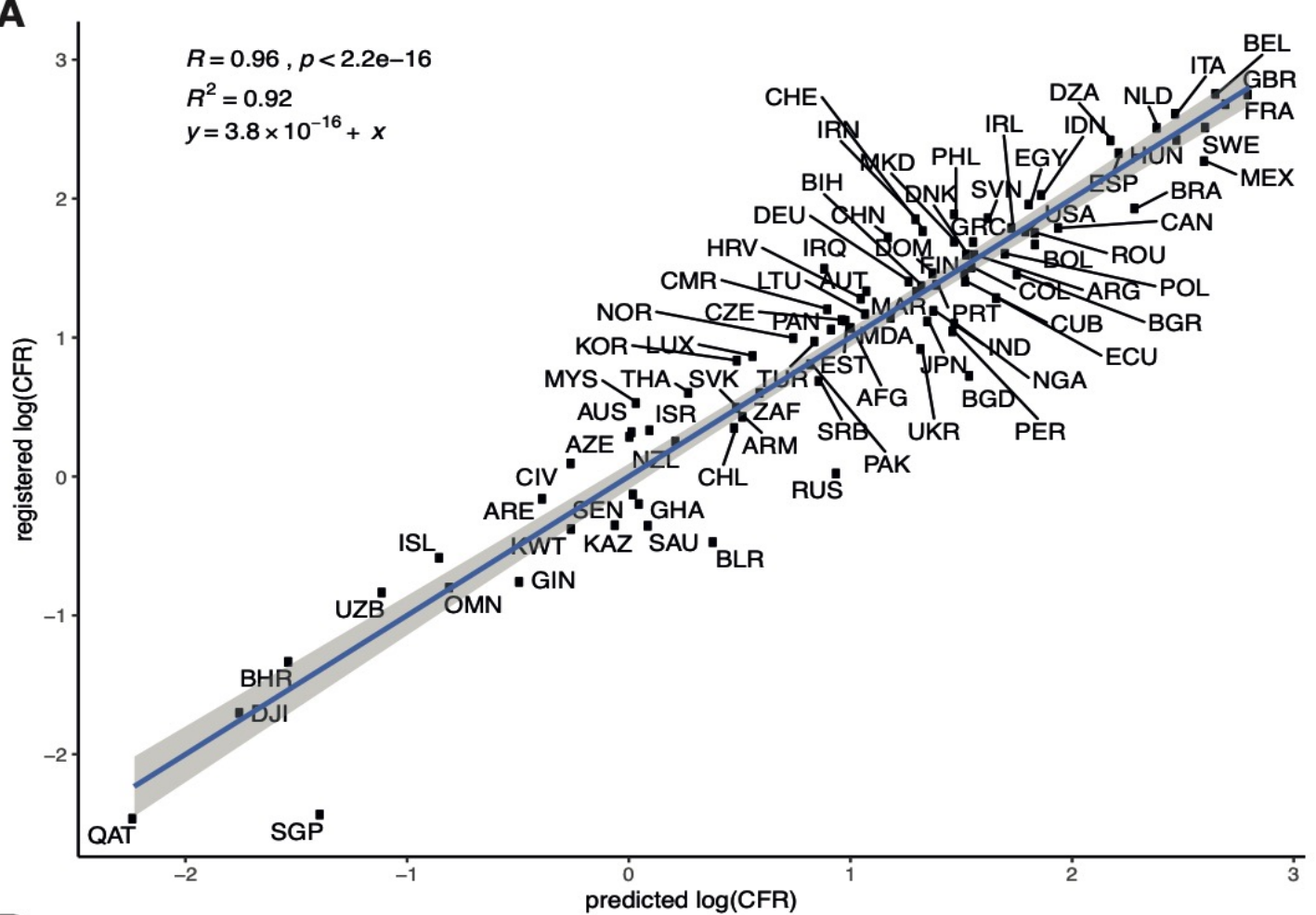

B

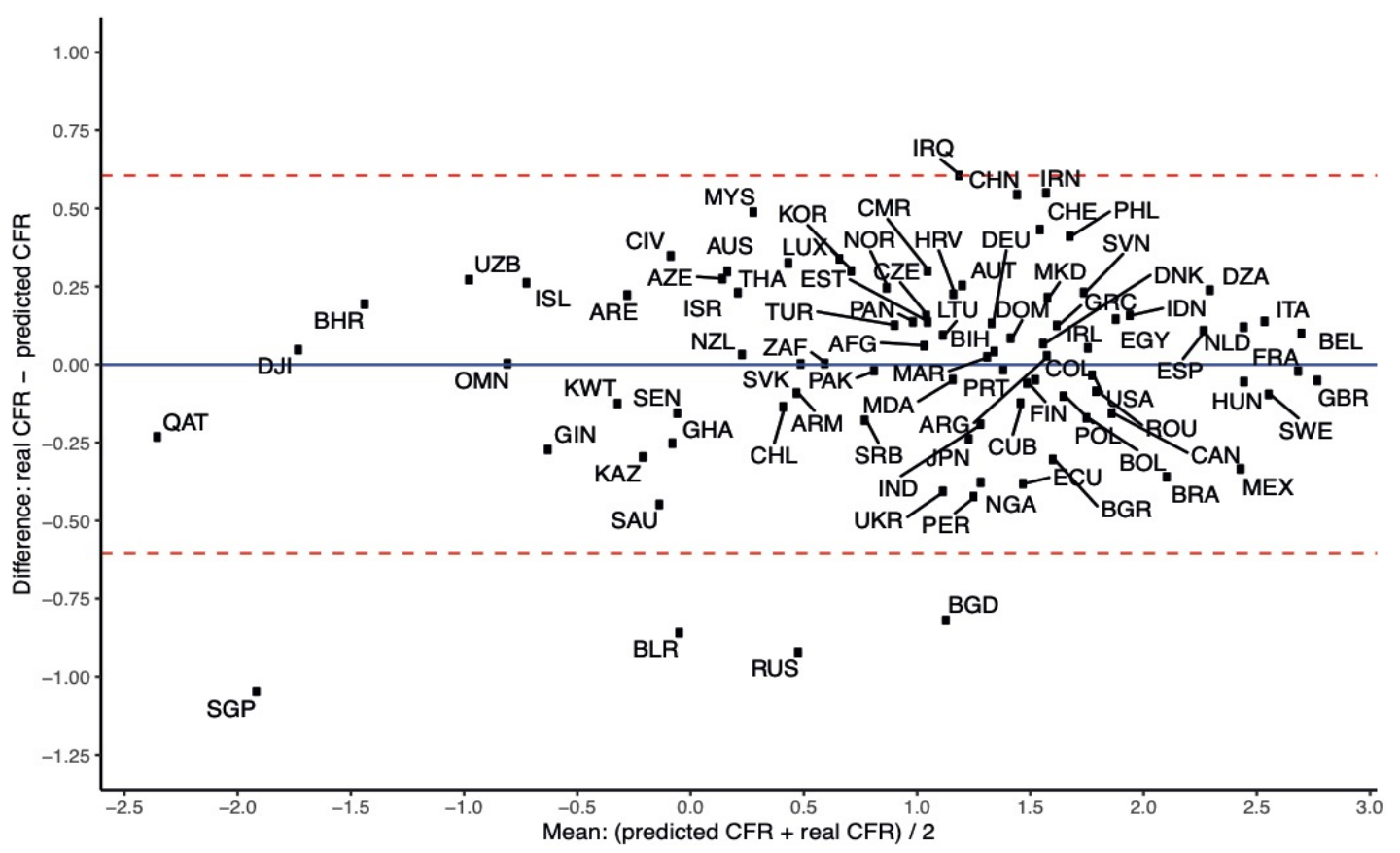

Figure 2. Agreement between observed and predicted case fatality rate (CFR). The countries are annotated with their country code. A. Predicted log-normalised $C F R$ (x axis) vs log-normalised observed CFR (y axis). The model could predict almost perfectly the CFR in a linear fashion. The blue line is model fit and the shades are $95 \% \mathrm{Cl}$; B. Bland-Altman plot. The mean of the predicted log-normalised CFR and observed log-normalised CFR is plotted on the $\mathrm{x}$ axis, whereas the difference on a log scale between the observed CFR and predicted CFRis plotted on the y axis. The mean difference between the observed CFR and predicted CFR was 0 (blue, full line), with the $95 \%$ confidence intervals (red, dashed lines) containing most of the values. Four countries were outliers in this model, having lower CFR than predicted: Russia, Belarus, Singapore, and Bangladesh. 
medRxiv preprint doi: https://doi.org/10.1101/2020.05.28.20114934; this version posted June 2, 2020. The copyright holder for this preprint (which was not certified by peer review) is the author/funder, who has granted medRxiv a license to display the preprint in perpetuity. It is made available under a CC-BY-NC-ND 4.0 International license .

On average, several countries had $>25$ more $n D_{p m}$ than expected - Italy, Belgium, Switzerland, Spain, the Netherlands, and Iran, whereas others had on average $>5$ less $n D_{p m}$ than expected - UK, Peru, Brazil, Belarus, Russia, Canada, Chile and Kuwait. Likewise, Italy, Algeria, Iran, the Netherlands, China, Belgium, Iraq, Indonesia, Spain, Switzerland, and the Philippines had on average $>1.5 \%$ higher CFR than expected according to the model, whereas Bangladesh, Ukraine, Brazil, Bolivia, Mexico, Belarus, Russia, Peru, and Honduras had on average $>1 \%$ lower $C F R$ than expected.

At prospective time-points in May, three countries had consistently higher than $100 \% C D R$, reporting more cases than expected: Singapore (range: 404-854\%), Iceland (range: 159-160\%), and Qatar (range: 121-210\%). Detailed results from the sensitivity analyses are available in supplementary information.

\section{Discussion}

Most of the global variance in $n D_{p m}$ between countries was explained by reported prevalence of SARS-CoV-2 infections $\left(n C_{p m}\right)$ and age distribution as expressed with the IFRadj. This has to be further adjusted for the $C D R$, which has an inverse relation with the $n D_{p m}$, but only in the context of using $n C_{p m}$ and $I F R_{a d j}$ to explain $n D_{p m}$. As expected, the richer countries were better at testing and detecting cases, but were also older and had a higher infection mortality burden. The $C F R$ is also dependent on the IFR $R_{a d j}$ and the $C D R$, but does not depend on the prevalence or the total number of SARSCoV-2 confirmed cases.

Some countries remain outliers, having consistently higher or lower mortality than expected according to the models. This is possibly due to consistent misreporting (10), differences in reporting deaths, diagnostic bias, sex distribution and average age of individuals who died countries with on average higher mortality than expected possibly had more older people and more men infected and dying.(15)

The observation that several countries have detected a higher number of cases than expected and had lower observed CFR than IFR adj (see supplementary

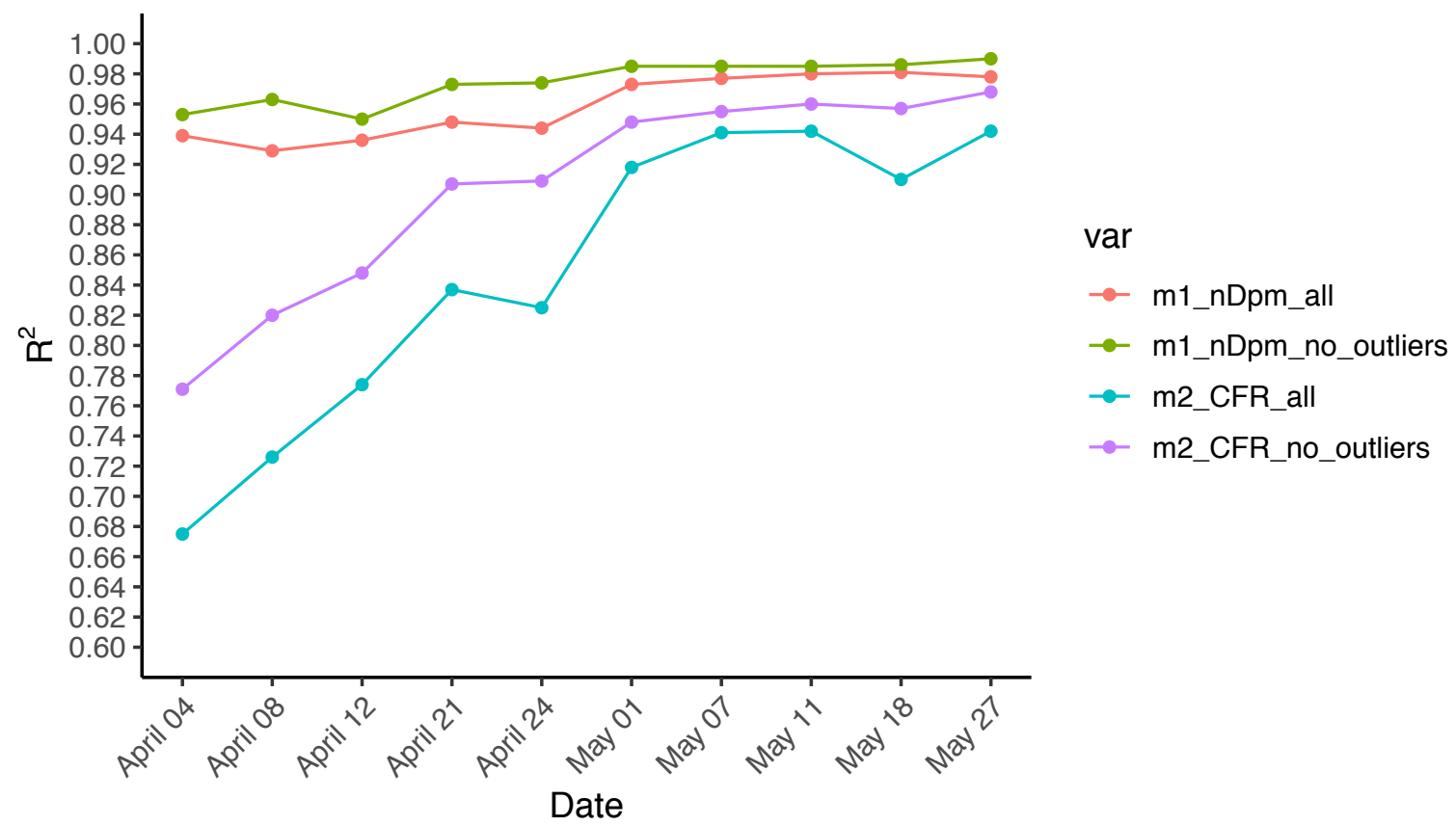

Figure 3. $R^{2}$ at ten time points of linear model 1 (explaining $n D_{p m}$ ) and linear model 2 (explaining $\boldsymbol{C F R}$ ). $\mathrm{m} 1 \_\mathrm{nDpm} \_$all, model 1 with all countries included; $\mathrm{m} 1 \_n D p m \_n o$ outliers, model 1 after excluding outliers; m2_CFR_all, model 2 with all countries included; m2_CFR_no_outliers, model 2 after excluding outliers. 
medRxiv preprint doi: https://doi.org/10.1101/2020.05.28.20114934; this version posted June 2, 2020. The copyright holder for this preprint

(which was not certified by peer review) is the author/funder, who has granted medRxiv a license to display the preprint in perpetuity. It is made available under a CC-BY-NC-ND 4.0 International license.

information), supports the notion that the current IFR is overestimated and that the actual mortality is lower than estimated. To confirm these observations, serological surveys of populations will be essential in correctly estimating the true prevalence and mortality of SARS-CoV-2.

\section{Strengths and limitations}

These models use very few explanators while maintaining high accuracy in explaining mortality. The sensitivity analyses demonstrated the robustness of the mathematical models when tested on real data. There is a remaining small proportion of variance than cannot be explained by the models, and this can be due to data mishandling or estimation errors, which limit the study. Independent of these limitations, the $n D_{p m}$ model remained robust. The CFR model was more sensitive to outliers than the $n D_{p m}$ model, and might be a less stable mortality outcome to follow SARS-CoV-2 mortality burden over time and across countries. The models were somewhat less accurate at earlier stages, which can be due to the amount of data (number of countries) used to build the models.

\section{Conclusions and policy implications}

Overall, this study demonstrates that most countries are on a similar SARS-CoV-2 mortality trajectory as the number of cases increases, after adjusting for age distribution and CDR. These models should be used for less biased comparisons of mortality between countries. The $n D_{p m}$ model appears as a more stable indicator of SARS-CoV-2 infection mortality burden and should be favoured in following and comparing mortality within and between countries.

\section{Evidence before this study}

- Verity and colleagues (Lancet Inf Dis 2020) have estimated the SARS-CoV-2 infection fatality rates (IFR) per age groups, and Vollmer \& Bommer (2020) have estimated that the average case detection rate $(C D R)$ of SARSCoV-2 infections in 40 countries was below $10 \%$ end of March.

- No studies have been published explaining the global SARS-CoV-2 variance in mortality. A medRxiv preprint by Shagam (2020) reports that approximately $60 \%$ of SARS-CoV-2 mortality variance can be explained by gross domestic product per capita in United States dollars (GDP), latitude, hemisphere, press freedom, population density, fraction of citizens over 65 years old, and outbreak duration.

\section{Added value of this study}

- The models in this study demonstrate that most of the between-countries variance in SARS-CoV-2 mortality can be explained with two to three explanators, maintaining high accuracy. This can help to alleviate public concerns of potential varying virulence of the virus, and provide a less biased, standardised comparison of mortality burden between countries.

- In the setting of lacking an effective and safe treatment and/or vaccine against SARS-CoV-2, most of the countries will be on a similar SARSCoV-2 mortality trajectory as the number of cases increases, after adjusting for the age distribution of the population and the case detection rate.

\section{References}

1. Studdert DM, Hall MA. Disease Control, Civil Liberties, and Mass Testing - Calibrating Restrictions during the Covid-19 Pandemic. N Engl J Med. 2020 Apr;

2. McKee M, Stuckler D. If the world fails to protect the economy, COVID-19 will damage health not just now but also in the future. Nat Med. 2020 Apr;

3. Worldometer. COVID-19 Coronavirus Pandemic [Internet]. 2020 [cited 2020 May 27]. Available from: https://www.worldometers.info/coronavirus/

4. European Centre for Disease Prevention and Control ECDC. Geographic distribution of COVID-19 cases worldwide [Internet]. [cited 2020 May 27]. Available from: https://www.ecdc.europa.eu/en/publications -data/download-todays-data-geographicdistribution-covid-19-cases-worldwide 
medRxiv preprint doi: https://doi.org/10.1101/2020.05.28.20114934; this version posted June 2, 2020. The copyright holder for this preprint

(which was not certified by peer review) is the author/funder, who has granted medRxiv a license to display the preprint in perpetuity. It is made available under a CC-BY-NC-ND 4.0 International license.

Global SARS-CoV-2 mortality variance

5. Bendavid E, Mulaney B, Sood N, Shah S, Ling E, Bromley-Dulfano R, et al. COVID-19 Antibody Seroprevalence in Santa Clara County, California. medRxiv [Internet]. 2020 Jan 1;2020.04.14.20062463. Available from: http://medrxiv.org/content/early/2020/04/30/ 2020.04.14.20062463.abstract

6. Li R, Pei S, Chen B, Song Y, Zhang T, Yang $W$, et al. Substantial undocumented infection facilitates the rapid dissemination of novel coronavirus (SARS-CoV-2). Science. 2020 May;368(6490):489-93.

7. Baud D, Qi X, Nielsen-Saines K, Musso D, Pomar L, Favre G. Real estimates of mortality following COVID-19 infection. The Lancet. Infectious diseases. United States; 2020.

8. Verity R, Okell LC, Dorigatti I, Winskill P, Whittaker C, Imai N, et al. Estimates of the severity of coronavirus disease 2019: a model-based analysis. Lancet Infect Dis. 2020 Mar;

9. Vollmer S, Bommer C. Average detection rate of SARS-CoV-2 infections is estimated around nine percent [Internet]. 2020 [cited 2020 May 12]. Available from: https://www.unigoettingen.de/en/606540.html

10. Shagam L. Untangling factors associated with country-specific COVID-19 incidence, mortality and case fatality rates during the first quarter of 2020. medRxiv [Internet]. 2020 Jan 1;2020.04.22.20075580. Available from:

http://medrxiv.org/content/early/2020/04/27/ 2020.04.22.20075580.abstract

11. United Nations, Department of Economic and Social Affairs, Population Dynamics UN. World Population Prospects 2019, Online Edition. [Internet]. 2020 [cited 2020 Apr 12]. Available from: https://population.un.org/wpp/Download/Sta ndard/Population/

12. UN Data, United Nations Statistics Division UN. Per capita GDP at current prices - US dollars [Internet]. 2020 [cited 2020 May 12]. Available from: https://data.un.org/Search.aspx?q=gdp

13. Bland JM, Altman DG. Statistical methods for assessing agreement between two methods of clinical measurement. Lancet (London, England). 1986 Feb;1(8476):30710.

14. Stevens GA, Alkema L, Black RE, Boerma JT, Collins GS, Ezzati M, et al. Guidelines for
Accurate and Transparent Health Estimates Reporting: the GATHER statement. Lancet (London, $\quad$ England). 2016 Dec;388(10062):e19-23.

15. Onder G, Rezza G, Brusaferro S. CaseFatality Rate and Characteristics of Patients Dying in Relation to COVID-19 in Italy. JAMA. 2020 Mar;

Acknowledgments: We express gratitude to Dr. Petter Brodin, Dr. Ioannis Siavelis, and Dr. Emilie Friberg for reading the draft and providing fruitful feedback.

Patient and public involvement: The study is conducted with publicly available data, and does not include individual patient or public involvement.

Ethical standards: The study was performed according to the ethical standards expressed in the Declaration of Helsinki. This study does not require ethical approval.

Contribution: HB designed the study, derived the hypotheses, collected, analysed and interpreted the data, and wrote and edited the manuscript. $\mathrm{JL}$ and MP assisted in design and interpretation of the study, supervised the work, reviewed and edited the manuscript.

Transparency: The corresponding author (HB) affirms that this manuscript is an honest, accurate, and transparent account of the study being reported; that no important aspects of the study have been omitted; and that any discrepancies from the study as planned have been explained.

Dissemination: not applicable.

Competing interests: The authors declare no conflict of interest.

Funding: The authors have not received funding for this work. 